\title{
Highly Active Pandanus Nanocellulose-supported Poly(amidoxime) Copper (II) Complex for Ullmann Cross- coupling Reaction
}

\author{
Md Lutfor Rahman ${ }^{1}$, Tang Xin Ting ${ }^{2}$, Mohd Sani Sarjadi ${ }^{3}$ and Choong Jian Fui ${ }^{4, *}$ \\ ${ }^{1}$ Faculty Science and Natural Resources, University Malaysia Sabah, Malaysia; lutfor73@gmail.com \\ 2 Faculty Science and Natural Resources, University Malaysia Sabah, Malaysia; tangxinting_0917@hotmail.com \\ ${ }^{3}$ Faculty Science and Natural Resources, University Malaysia Sabah, Malaysia; msani@ums.edu.my \\ ${ }^{4}$ Faculty Science and Natural Resources, University Malaysia Sabah, Malaysia; jianfui@hotmail.com \\ ${ }^{*}$ Correspondence: jianfui@hotmail.com
}

\begin{abstract}
The transition metal-catalyzed chemical transformation of organic electrophiles, and organometallic reagents have turned up as an exceedingly robust synthetic tool. The evolution of transition metal catalysts has attained a stage of civilization that authorizes for an extensive scope of chemical bonds formation partners to be combined efficiently. The applications of Cu-based nanoparticles have received great attention owing to the earth-abundant, low toxicity and inexpensive. Due to these characteristics, copper nanoparticles have generated a great deal of interest especially in the field of catalysis. In this study, poly(acrylonitrile) was synthesized by undergoes free-radical initiation process and followed by Beckmann rearrangement with hydroxylamine solution converted into the poly(amidoxime) ligand and anchored the copper onto poly(amidoxime). $\mathrm{Cu}(\mathrm{II}) @ \mathrm{PAM}$ was characterized using different techniques such as FTIR, FESEM, EDX, TEM, TGA, DSC, ICP-OES and XPS analyses. The Cu(II)@PAM showed high stability and high catalytic activity in a wide variety of electrophilic substituted phenols with substituted aryl/benzyl halides. $0.03 \mathrm{~mol} \%$, $\pm 3 \mathrm{mg}$ of $\mathrm{Cu}(\mathrm{II}) @ \mathrm{PAM}$ could efficiently promoted Ullmann reaction to give the corresponding coupling product up to $99 \%$ yields. The complex was easy separated and recovered from the reaction mixture by simple filtration.
\end{abstract}

Keywords: Pandanus nanocellulose, Poly(amidoxime), Copper (II) complex, Ullmann reaction, CO bond formation

\section{Introduction}

The formation of a diaryl ether linkage/ aryl-O bond is a vital reaction as it produces numerous chemical intermediates that have been proved to have significant importance in biology, pharmaceutical, life science, and material interest [1]. Owing to some disadvantages given by the conventional method of diaryl ether formation [2], researchers have shifted their attention to the copper-catalyzed Ullmann coupling reaction. However, the classic Ullmann reaction requires a high temperature, excessive usage of copper catalyst, limitation of substrate scope and production of moderate yield [3]. Therefore, development of economical, environment friendly and recyclable is highly desirable for organic transformation. Despite the fact that the usage of heterogeneous copper catalysts is preferential over their homogenous counter partner owing to easy separation of product and reusability of catalyst, their use still faces some issues related to agglomeration due to the high surface energy in an aqueous environment [4]. To overcome this problem, copper particles are immobilized on a solid support such as cellulose [5]. Cellulose, the most abundant polysaccharides in nature, have been used as supports due to their biodegradability, environmentally friendly, costeffectiveness, water insolubility and reactivity of its hydroxyl groups [6]. Pure cellulose obtaining from the food and agricultural industrial waste does not have high adsorption capacity, resulting in the removal of trace levels of metals become ineffective. Its adsorption ability can be improved by simple chemical modifications of its surface [6-8] and therefore, the newly formed surface will posess ionic or covalent interaction with heavy metals in the aqueous environment $[6,9]$. 
In this report we anchored copper NPs onto pandanus nanocellulose poly(amidoxime) as an efficient heterogeneous catalyst for $\mathrm{C}-\mathrm{O}$ bond formation. The $\mathrm{Cu}(\mathrm{II}) @ \mathrm{PAM}$ were found greatly effective in the $\mathrm{C}-\mathrm{O}$ bond formation reactions. The catalyst was easy to recover and reused without any significant loss of their catalytic activity.

\section{Methedology}

\subsection{Synthesis of nanocellulose:}

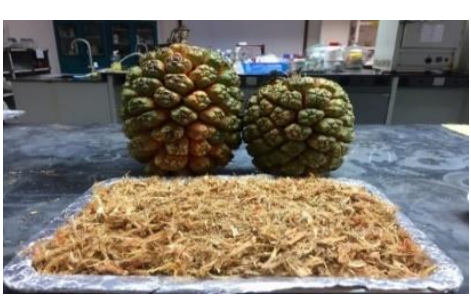

Figure 1. Pandanus fruit

Pandanus fruits were collected from Papar in Sabah, Malaysia (Figure 1). The cellulose pulp was extracted from waste pandanus fruit fiber according to the method described elsewhere [10]. The nanocellulose was prepared by stirring $5.0 \mathrm{~g}$ of pandanus cellulose pulp in $250 \mathrm{~mL} 40 \%$ of conc. sulphuric acid for $1.5 \mathrm{~h}$ with well shaking. After the reaction, the resultant product was directly poured into cold water to stop the reaction. Then the nanocellulose was washed with water until it became neutral. The product was dried in over for $50^{\circ} \mathrm{C}$ for one day to get a constant weight.

\subsection{Graft Copolymerisation; PAC:}

About $5.0 \mathrm{~g}$ of nanocellulose put in $500 \mathrm{~mL}$ of distilled water. Then $3 \mathrm{~mL}$ of the conc. $\mathrm{H}_{2} \mathrm{SO}_{4}$ was added to the mixture followed by $2.0 \mathrm{~g}$ of ceric ammonium nitrate. $15 \mathrm{~mL}$ of purified acrylonitrile solution was added into the mixture and stirred for $5 \mathrm{~h}$ under the inert condition at $60^{\circ} \mathrm{C}$ (Scheme 1). At the end of reaction, the mixture was precipitated out by excess amount of methanol. The resultant product was then dried in an oven at $55^{\circ} \mathrm{C}$ to obtain a constant weight.

\subsection{Synthesis of Nanocellulose-based Poly(amidoxime) Chelating Ligand; PAM:}

About $20.0 \mathrm{~g}$ of hydroxylamine hydrochloride was dissolved in $500 \mathrm{~mL}$ of methanolic solution. Then about $50 \%$ of $\mathrm{NaOH}$ solution was added in the cold condition, and the precipitate $\mathrm{NaCl}$ salt was filtered out. $10.0 \mathrm{~g}$ of PAC and $100 \mathrm{~mL}$ of hydroxylamine solution were added into a reagent bottle and the reaction was carried out at $80^{\circ} \mathrm{C}$ for six hours. The resultant product was filtered out and washed using methanol. Then PAM was dried in an oven at $55^{\circ} \mathrm{C}$ to obtain a constant weight.

\subsection{Preparation of $\mathrm{Cu}(\mathrm{II}) @ P A M:$}

$10.0 \mathrm{~g}$ of PAM was added into $1 \mathrm{M}$ of copper (II) sulphate solution $\left(9.33 \mathrm{~g}, 50 \mathrm{~mL} \mathrm{H}_{2} \mathrm{O}\right.$ ) at room temperature. The yellow color of the PAM should be immediately turned into dark green colour, and the mixture was filtered out and washed with methanol and dry at $60^{\circ} \mathrm{C}$ for one day. The ICP-OES analysis was used to estimate the copper adsorbed by the amidoxime ligand (Scheme 1).

\subsection{General Procedure for the Ullmann Etherification Cross-Coupling Reaction:}

$\pm 0.3 \mathrm{mg}$ of $\mathrm{Cu}(\mathrm{II}) @ \mathrm{PAM}$ was added into a mixture of aryl halide/benzyl halide (1.0mmol), phenol $(1.2 \mathrm{mmol})$ and $\mathrm{K}_{2} \mathrm{CO}_{3}(3 \mathrm{mmol})$ in acetonitrile $(5 \mathrm{~mL})$ at $50^{\circ} \mathrm{C}$. The corresponding product was monitored by TLC and GC analyses. The metal catalyst was separated by filtration after the reaction. The corresponding product was extracted with dichloromethane. The crude product was purified by silica gel column (ethyl acetate/hexane) to give the corresponding cross-coupling product [11].

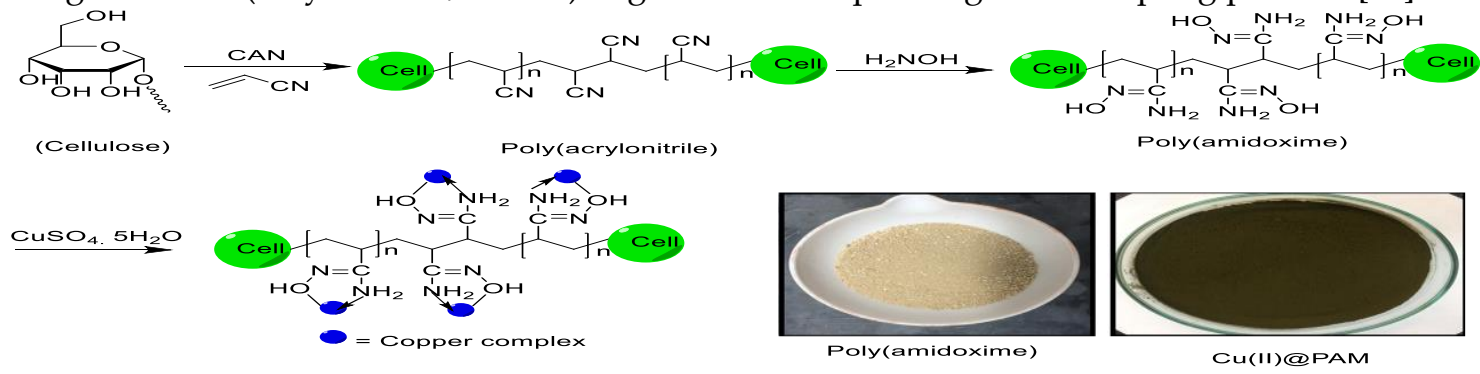

Scheme 1. Preparation of $\mathrm{Cu}(\mathrm{II}) @ \mathrm{PAM}$ 


\section{Result and Discussion}

The bio-waste pandanus nanocellulose-supported poly(acrylonitrile) and poly(amidoxime) ligand were prepared and characterized (FTIR) according to early report [10,12]. The amidoxime ligand was anchored with copper at room temperature to give dark green color $\mathrm{Cu}(\mathrm{II}) @ \mathrm{PAM}$ (Scheme 1). The ICP-OES showed that $0.50 \mathrm{mmol} / \mathrm{g}$ of copper was coordinated with the PAM.

\subsection{FE-SEM, TEM and EDX Analysis}

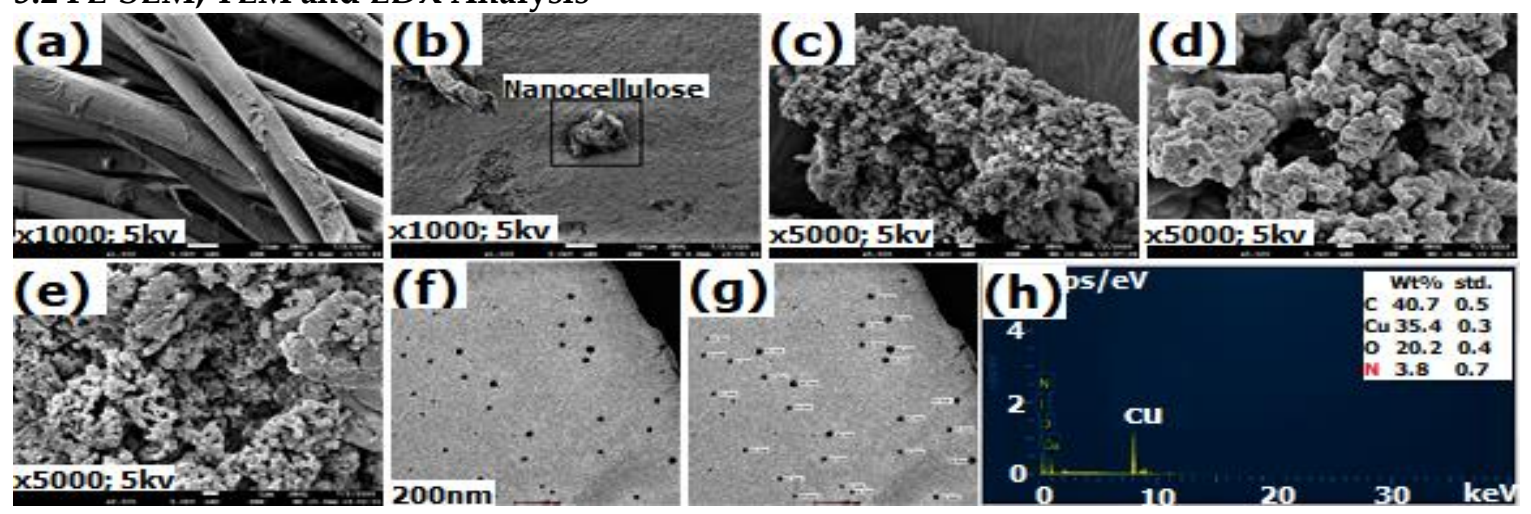

Figure 2. FE-SEM image of (a) pandanus cellulose, (b) nanocellulose, (c) poly(acrylonitrile), (d) poly(amidoxime), (e) Cu(II)@PAM; (f) TEM image of Cu(II)PAM, (g) TEM image of Cu(II)PAM with measurement; (h) EDX image of $\mathrm{Cu}(\mathrm{II}) @ \mathrm{PAM}$.

After chemical treatment of fibre, pandanus cellulose pulp showed noticeably smooth wooden sticklike structure (Figure 2a). Followed by the nanocellulose (Figure 2b) showed the same morphology as cellulose pulp. The only difference between pandanus cellulose pulp and nanocellulose are the size of and shape. PAC presented with a rough surface with deformed spherical-like morphologies (Figure 2c). In PAM ligand, an unsmooth structural surface with a distinguishable small sphere shape was observed (Figure 2d). Continued, Cu(II)@PAM showed smaller spherical shapes with similar accumulation was observed, as shown in Figure 2e.

The TEM analysis of the $\mathrm{Cu}(\mathrm{II}) @ \mathrm{PAM}$ was showed the presence of copper onto the PMA surface (Figure 2f) and the average nanoparticles size of copper $\emptyset=27.51 \pm 2 \mathrm{~nm}$ was measured (Figure $2 \mathrm{~g}$ ). The copper nanoparticles exhibited spherical morphology with no agglomeration occur. As shown in Figure 2f, a random distribution of copper nanoparticles was well distributed on the PAM surface.

Figure $2 \mathrm{~h}$ represents the EDX spectra of $\mathrm{Cu}(\mathrm{II}) @ \mathrm{PAM}$ after anchoring the copper. Upon the inspection of the result, it is evidence that the value of copper has been increased after evacuated of copper in the copper solution. It can seem that around $35.4 \%$ of copper anchored on the PAM.

\subsection{Thermogravimetry Analysis}

The thermal behaviour of the cellulose, poly(acrylonitrile), poly(amidoxime) ligand and $\mathrm{Cu}(\mathrm{II}) @ \mathrm{PAM}$ were performed with heating rate $10 \mathrm{~min}^{-1}$ in nitrogen condition and the obtained result was presented in Figure 3. In the complete analysis, there are several changes in 4 materials with the elevation of the sample temperature. A small weight loss was notified in 4 materials before $150^{\circ} \mathrm{C}$. These may have resulted from the remaining water molecules and volatile organic solvent that are located in the external surface and internal cavities of the synthesize materials. The cellulose TA curve shows that there is a significant weight loss at around $315-390^{\circ} \mathrm{C}$ due to the degradation of $-\mathrm{OH}$ and $-\mathrm{CH}_{2} \mathrm{OH}$ function group (Figure 3d) [13]. The PAC was degraded in temperature range $285-550^{\circ} \mathrm{C}$. The first weight loss $(\sim 40 \%)$ at about $285-400^{\circ} \mathrm{C}$ was due to the dehydrogenation reaction and degradation of the cyanide group. The second stage of the weight loss ( 15\%) was started at $400-550$ ${ }^{\circ} \mathrm{C}$ and could belong to the degradation of the remaining of acrylonitrile chain (Figure 3c) [14]. The poly(amidoxime) ligand was degraded from $175-455^{\circ} \mathrm{C}$ due to the degradation of the amidoxime functional group (Figure $3 \mathrm{~b}$ ). The total weight loss of PAM is $50 \%$ while PAC is $60 \%$. Overall, PAM and $\mathrm{Cu}(\mathrm{II}) @ \mathrm{PAM}$ were more stable than their precursors, which has good nature in term of degradation behaviour of final product. 


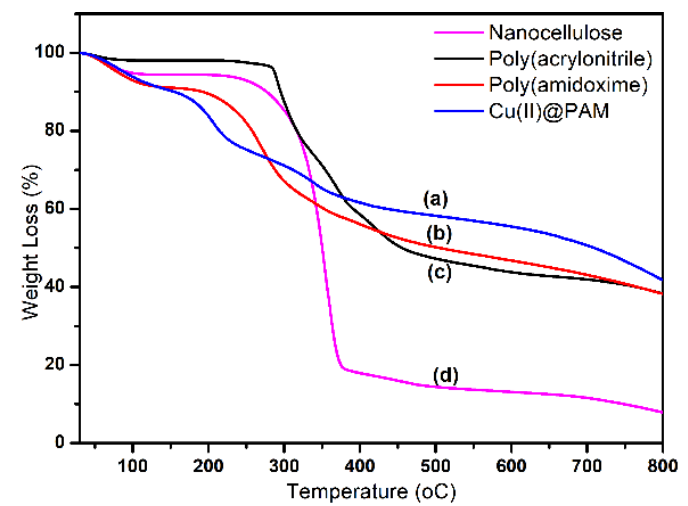

Figure 2. left: TG graph of nanocellulose, poly(acrylonitrile), poly(amidoxime and $\mathrm{Cu}(\mathrm{II}) @ \mathrm{PAM}$

\subsection{X-ray photoelectron spectroscopy analysis (XPS)}

Amidoximes are the bidentate ligands which are efficiently bound with copper due to the strong chelating ability to transition metal ions. The X-ray photoelectron spectra are acquired to explain the binding mechanisms of copper on the PAM. The wide scan XPS spectra of $\mathrm{Cu}(\mathrm{II}) @ \mathrm{PAM}$ and pure PAM were shown in Figure 4a. The binding energies (BEs) peaks in Figure 4a were found at 287.5, 402.0 and $534.0 \mathrm{eV}$ corresponding to the $\mathrm{C} 1 \mathrm{~s}, \mathrm{~N}$ 1s, and $\mathrm{O}$ 1s spectra, respectively. The binding of $\mathrm{Cu}(\mathrm{II})$ is confirmed by the presence of two new peaks with BEs of 935.5 and $952.0 \mathrm{eV}$ for the signals of Cu2p3/2 and Cu2p1/2 as shown in Figure 4a(i). The O 1's XPS spectra of the pure PAM showed two peaks at the BEs of 531.5 and $534.0 \mathrm{eV}$, which correspond to the oxygen atoms in the $\mathrm{C}-\mathrm{OH}$ and $\mathrm{C}=\mathrm{N}-\mathrm{OH}$ species, respectively. After binding with copper, a new peak at a $\mathrm{BE}$ of $531.0 \mathrm{eV}$ belonging to the peaks of $\mathrm{O} 1 \mathrm{~s}$ of the oxygen atoms in $\mathrm{C}=\mathrm{N}-\mathrm{OH}$ was formed (Figure 4c).

In the core-level $\mathrm{N} 1 \mathrm{~s}$ spectra for the PAM, the $\mathrm{N}$ 1s peak of polymer ligand showed two peaks at the BEs of 402.0 and $398.5 \mathrm{eV}$, which correspond to nitrogen atoms in $\mathrm{C}-\mathrm{NH}_{2}$ and $\mathrm{C}=\mathrm{N}-\mathrm{OH}$ species, respectively. After PAM was bonded with copper, a new peak for the $\mathrm{N} 1 \mathrm{~s}$ was found with a BE of $402.5 \mathrm{eV}$ owing to the coordinated bond of the amidoxime group with copper.

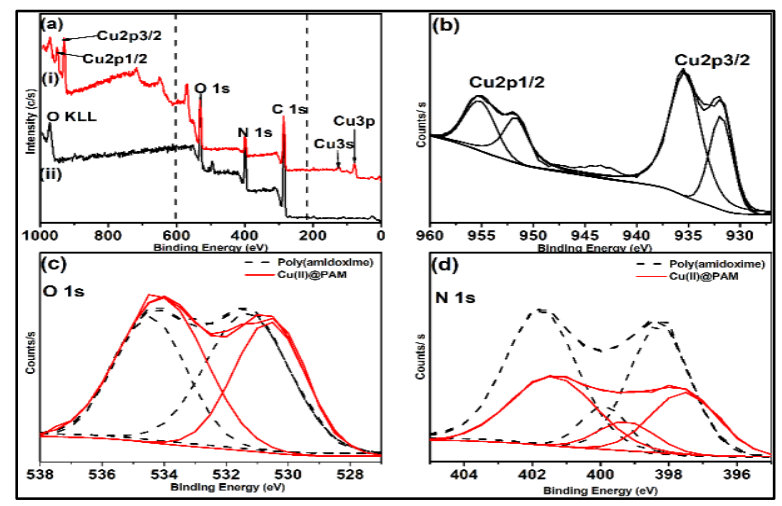

Figure 3. (ai)Survey scan XPS of $\mathrm{Cu}(\mathrm{II}) @ P A M$, (aii) Survey Scan XPS of PAM before enchored copper; (b) curve fitting XPS of $\mathrm{Cu}(\mathrm{II}) @ P A M ;$ (c) curve fitting XPS of O 1s; (d) curve fitting XPS of N 1s.

\subsection{Copper (II) catalyzed Ullmann Etherification coupling reaction}

The performance of $\mathrm{Cu}(\mathrm{II}) @ \mathrm{PAM}$ was examined in the Ullmann reaction of phenol and benzyl halide. The initial reaction was performed using $15.0 \mathrm{mg}$ of $\mathrm{Cu}(\mathrm{II}) @ \mathrm{PAM}$ at $80^{\circ} \mathrm{C}$ for $8 \mathrm{~h}$ in presence $3 \mathrm{~mol}$ of $\mathrm{K}_{2} \mathrm{CO}_{3}$ and $5 \mathrm{ml}$ of acetonitrile. It was found that $\mathrm{Cu}(\mathrm{II}) @ \mathrm{PAM}$ can afford to correspond product in $98 \%$ yield (Table 1, entry 1 ) smoothly. We also accomplish the reaction by changing the catalyst loading, time and temperature and eventually found that $\pm 3.0 \mathrm{mg}$ of $\mathrm{Cu}(\mathrm{II}) @ \mathrm{PAM}, 2 \mathrm{~h}$ of reactions time and the reaction conduct at $50^{\circ} \mathrm{C}$ shall be sufficient to bring forward the reaction efficiently.

Table 1: Screening of Ullmann cross-coupling reaction

\begin{tabular}{ccccc}
\hline Entry & $\mathrm{Cu}(\mathrm{II}) @ \mathrm{PAM}(\mathrm{mg})$ & Temperature $\left({ }^{\circ} \mathrm{C}\right)$ & Time $(\mathrm{h})$ & Yield $(\%)$ \\
\hline 1 & 15 & 80 & 8 & 98
\end{tabular}




\begin{tabular}{lcccc}
2 & 5 & 50 & 8 & 99 \\
3 & 3 & 50 & 2 & 99 \\
4 & 1.5 & 50 & 2 & 89 \\
\hline
\end{tabular}

- Conditions: 4-nitrobenzyl bromide $(1 \mathrm{mmol})$, phenol $(1.2 \mathrm{mmol})$, a catalytic amount of complex copper and 3 mol equiv. of $\mathrm{K}_{2} \mathrm{CO}_{3}$ in $5 \mathrm{~mL}$ of acetonitrile.

To prospect the extensive applicability of $\mathrm{Cu}(\mathrm{II}) @ \mathrm{PAM}$ in the Ullmann etherification, plenty of structurally diverse of phenol-substituted compound and phenyl halide/benzyl halide compound were used under earlier settled optimized reaction conditions and the result are summarized in Table 2. As illustrated in Table 2, this $\mathrm{Cu}(\mathrm{II}) @ P A M$ could efficiently drive these reactions toward the desired product in good to excellent yield. Phenol derivatives with both electron-donating and electronwithdrawing groups proceed smoothly with very good efficiency to form the desired products in high yields (77-99\%); (Table 2).

Table 2. Ullmann reaction of substituted benzyl halide and phenol derivatives compound

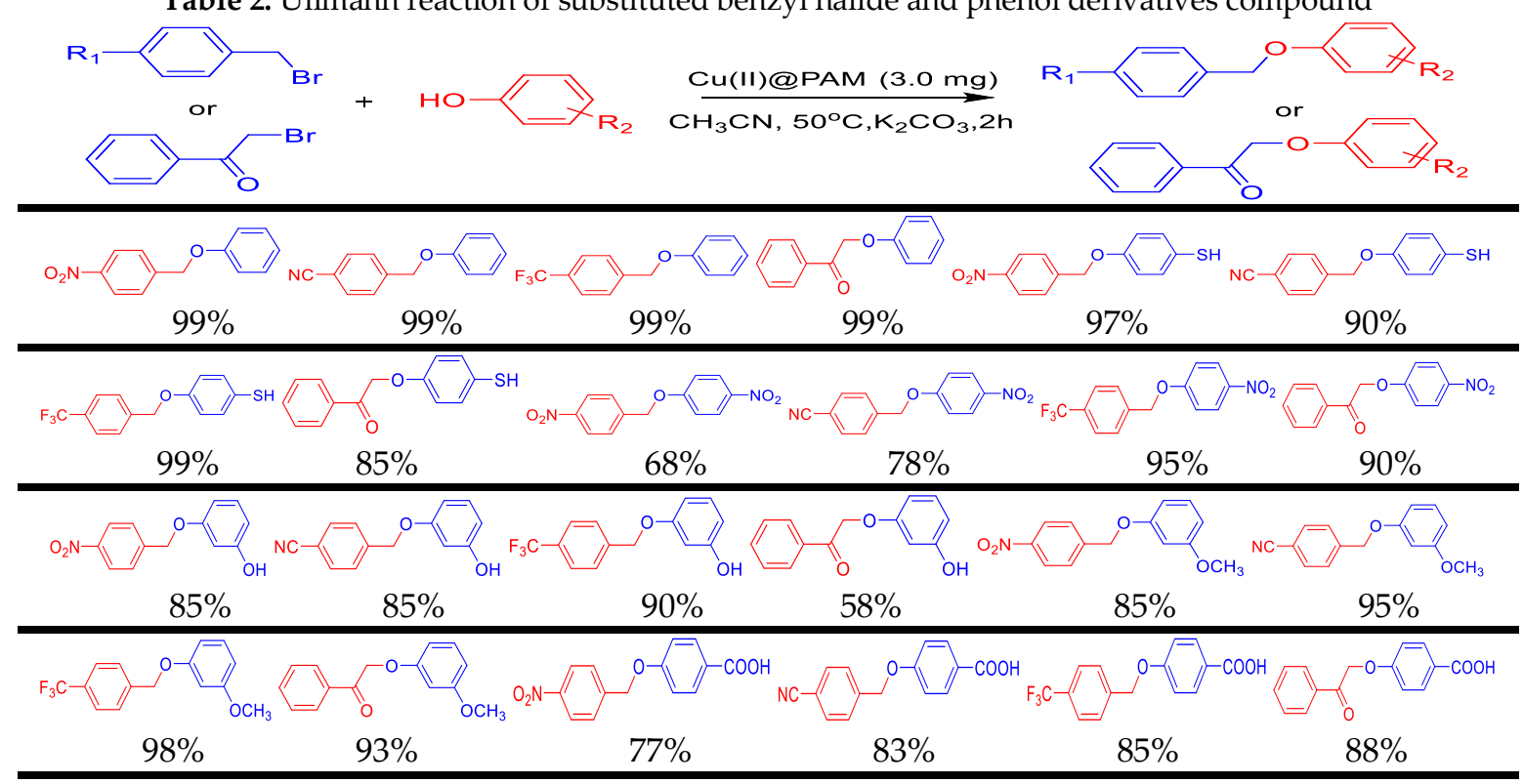

- $\quad$ Conditions: Benzyl halide (1 mmol), phenol (1.2 mmol), $\pm 3.0 \mathrm{mg}$ of $\mathrm{Cu}(\mathrm{II}) @ \mathrm{PAM}$ and $3 \mathrm{~mol}$ equiv. of $\mathrm{K}_{2} \mathrm{CO}_{3}$ in $5 \mathrm{~mL}$ of acetonitrile. All the compound was determined by GC-MS and NMR.

The aryl halide compound also used to investigate the applicability of $\mathrm{Cu}(\mathrm{II}) @ \mathrm{PAM}$. This is because the halogen group is direct-attached to sp2 hybridized carbon of benzene ring and hence, more electronegative and more challenging to break [16]. Within this part of the study, the result suggested that the aryl halide substituted with electron-withdrawing groups achieved a better yield compare to the electron-donating group. The reactivity of the aryl halide was following the general reaction, which $\mathrm{Ph}-\mathrm{I}>\mathrm{Ph}-\mathrm{Br}>\mathrm{Ph}-\mathrm{Cl}$ (Table 3). Besides, the aryl chloride was significantly affected by the substituent that attached to it. For example, neutral chlorobenzene provided only $20 \%$ of diphenyl ether product, whereas 4-cyanochlorobenzene afforded the respective product with $65 \%$ yield. In the study, the aryl-bromide substituted with bromo and nitro together give a reasonable result (65\%-75\%); (Table 3).

Table 3. Ullmann reaction of substituted aryl halide and phenol compound

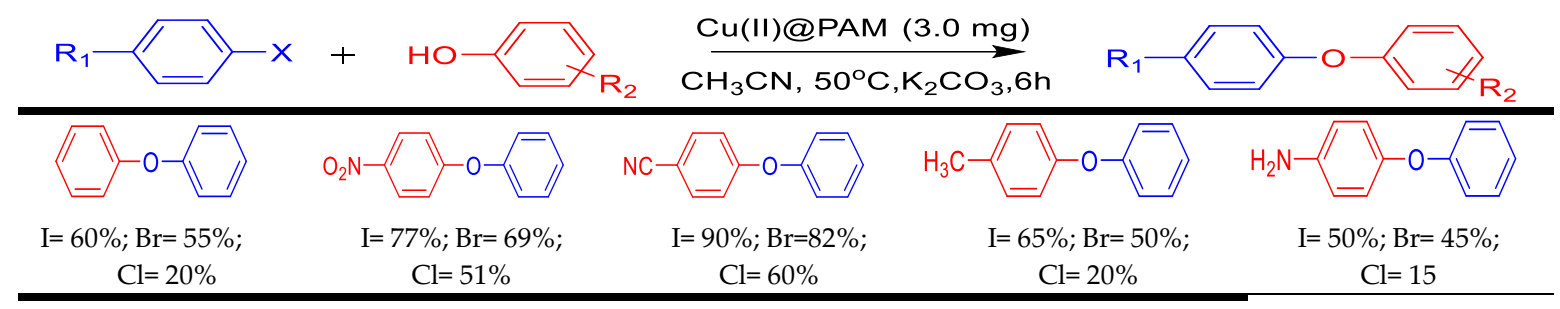




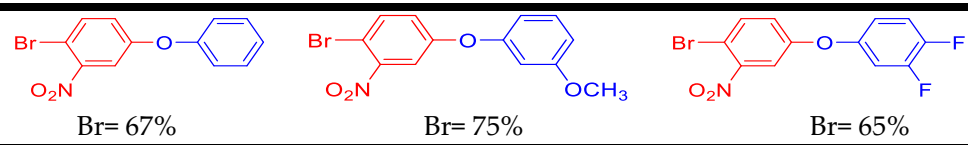

- $\quad$ Conditions: Benzyl halide (1 mmol), phenol (1.2 mmol), $\pm 3.0 \mathrm{mg}$ of $\mathrm{Cu}(\mathrm{II}) @ \mathrm{PAM}$ and $3 \mathrm{~mol}$ equiv. of $\mathrm{K}_{2} \mathrm{CO}_{3}$ in $5 \mathrm{~mL}$ of acetonitrile. All the compound was determined by using GC-MS and NMR.

\section{Conclusion:}

In summary, we have synthesised pandanus fruit fiber nanocellulose supported-poly(amidoxime) copper (II) complex which it was successfully applied in the Ullmann Etherification cross-coupling reaction with different substituted compound. The catalyst efficiency $( \pm 3.0 \mathrm{mg})$ promoted Ullmann cross-coupling reaction to produce corresponding products with satisfying yields. Moreover, the catalyst can be easily filtered out after the reaction is done.

\section{References:}

1.Cristau, H.-J.; Cellier, P. P.; Hamada, S.; Spindler, J.-F.; Taillefer, M., A General and Mild Ullmann-Type Synthesis of Diaryl Ethers. Organic Letters 2004, 6 (6), 913-916.

2.Puthiaraj, P.; Ahn, W.-S., Synthesis of copper nanoparticles supported on a microporous covalent triazine polymer: an efficient and reusable catalyst for O-arylation reaction. Catalysis Science \& Technology 2016, 6 (6), 1701-1709.

3.Liu, X.; Chang, S.; Chen, X.; Ge, X.; Qian, C., Efficient Ullmann C-X coupling reaction catalyzed by a recoverable functionalized-chitosan supported copper complex. New Journal of Chemistry 2018, 42 (19), 1601316020.

4.Taherinia, Z;; Ghorbani-Choghamarani, A., Cu(I)--PNF, an organic-based nanocatalyst, catalyzed C-O and C$S$ cross-coupling reactions. Canadian Journal of Chemistry 2019, 97, 46+.

5.Shi, X.-L.; Chen, Y.; Hu, Q.; Zhang, W.; Luo, C.; Duan, P., A Potential Industrialized Fiber-Supported Copper Catalyst for One-pot Multicomponent CuAAC Reactions in Water. Journal of Industrial and Engineering Chemistry 2017, 53.

6.Silva, L. S.; Carvalho, J.; Bezerra, R. D. S.; Silva, M. S.; Ferreira, F. J. L.; Osajima, J. A.; da Silva Filho, E. C., Potential of Cellulose Functionalized with Carboxylic Acid as Biosorbent for the Removal of Cationic Dyes in Aqueous Solution. Molecules (Basel, Switzerland) 2018, 23 (4).

7.Liu, L.; Xie, J. P.; Li, Y. J.; Zhang, Q.; Yao, J. M., Three-dimensional macroporous cellulose-based bioadsorbents for efficient removal of nickel ions from aqueous solution. Cellulose 2016, 23 (1), 723-736.

8.Rahman, M. L.; Sarkar, S. M.; Yusoff, M. M., Efficient removal of heavy metals from electroplating wastewater using polymer ligands. Frontiers of Environmental Science \& Engineering 2016, 10 (2), 352-361.

9.Kumari, S.; Mankotia, D.; Chauhan, G. S., Crosslinked cellulose dialdehyde for Congo red removal from its aqueous solutions. Journal of Environmental Chemical Engineering 2016, 4 (1), 1126-1136.

10.Jianfui, C.; Sarjadi, M.; Musta, B.; Sarkar, M.; Rahman, M. L., Synthesis of Sawdust-based Poly(amidoxime) Ligand for Heavy Metals Removal from Wastewater. ChemistrySelect 2019, 4, 2991-3001.

11.Mondal, S., Recent advancement of Ullmann-type coupling reactions in the formation of C-C bond. ChemTexts 2016, 2 (4), 17.

12.Rahman, M. L.; Sarjadi, M. S.; Arshad, S. E.; Yusoff, M. M.; Sarkar, S. M.; Musta, B., Kenaf cellulosebased poly(amidoxime) ligand for adsorption of rare earth ions. Rare Metals 2019, 38 (3), 259-269.

13.Rahman, M. L.; Fui, C. J.; Sarjadi, M. S.; Arshad, S. E.; Musta, B.; Abdullah, M. H.; Sarkar, S. M.; O'Reilly, E. J., Poly (amidoxime) ligand derived from waste palm fiber for the removal of heavy metals from electroplating wastewater. Environmental Science and Pollution Research 2020, 27 (27), 34541-34556.

14.El-Bahy, S. M.; El-Bahy, Z. M., Synthesis and characterization of polyamidoxime chelating resin for adsorption of $\mathrm{Cu}(\mathrm{II}), \mathrm{Mn}(\mathrm{II})$ and $\mathrm{Ni}(\mathrm{II})$ by batch and column study. Journal of Environmental Chemical Engineering 2016, 4 (1), 276-286.

15.Furushima, Y.; Nakada, M.; Takahashi, H.; Ishikiriyama, K., Study of melting and crystallization behavior of polyacrylonitrile using ultrafast differential scanning calorimetry. Polymer 2014, 55 (13), 3075-3081.

16.Alabugin, I. V.; Bresch, S.; Manoharan, M., Hybridization Trends for Main Group Elements and Expanding the Bent's Rule Beyond Carbon: More than Electronegativity. The Journal of Physical Chemistry A 2014, 118 (20), 3663-3677.

(C) 2019 by the authors; licensee MDPI, Basel, Switzerland. This article is an open access article distributed under the terms and conditions of the Creative Commons Attribution (CC-BY) license (http://creativecommons.org/licenses/by/4.0/). 